\title{
Distribution of Neuropeptide Y-like Immunoreactivity and Its Relationship to FMRF-amide-like Immunoreactivity in the Sixth Lumbar and First Sacral Spinal Cord Segments of the Rat ${ }^{1}$
}

\author{
CATHRINE A. SASEK AND ROBERT P. ELDE ${ }^{2}$
}

Department of Anatomy, University of Minnesota, Minneapolis, Minnesota 55455

\begin{abstract}
The present study was aimed at describing the distribution of neuropeptide $Y$ (NPY)-like immunoreactivity in the sixth lumbar (L6) and first sacral segments (S1) of the rat spinal cord, comparing this distribution to that of FMRF-amide-like immunoreactivity and determining whether NPY- and FMRFamide-like immunoreactivities are present in the same neurons in the dorsal gray commissure (DGC) in L6 and S1 of the rat spinal cord.
\end{abstract}

For distribution studies tissue from colchicine-treated animals was processed according to the peroxidase-antiperoxidase technique using anti-NPY as the primary antiserum. For co-localization studies serial $5-\mu \mathrm{m}$ sections were processed for immunofluorescence. Adjacent sections were incubated with either anti-NPY or anti-FMRF-amide as the primary antiserum. The number of immunoreactive cells per section was counted and each section was photographed. The sections were then restained with the other antiserum (i.e., tissue first stained with anti-NPY was stained with antiFMRF-amide and vice versa), the number of cells per section was recounted, and the sections were rephotographed.

NPY-like immunoreactive cells and fibers were identified in the DGC, sacral parasympathetic nucleus, substantia gelatinosa, marginal zone, nucleus proprius, and ventral horn. Every cell in the DGC that contained NPY-like immunoreactivity was found also to contain FMRF-amide-like immunoreactivity, and the distribution of NPY-like immunoreactive fibers was found to be similar, although denser than FMRFamide-like immunoreactive fibers.

The distribution of NPY-like immunoreactivity in L6 and S1 of the rat spinal cord suggests that an NPY-like peptide may be involved in regulation of pelvic viscera, processing of primary afferent information, and motor regulation of pelvic muscles. The presence of NPY- and FMRF-amide-like immunoreactivities in the same neurons in the DGC together with the lack of bona fide FMRF-amide in the rat central nervous system, the presence of NPY in the rat central nervous system, and the cross-reactivity of anti-FMRF-amide with NPY support the hypothesis that the FMRF-amide antiserum recognizes an NPY-like peptide in the rat spinal cord.

Received June 18, 1984; Revised December 10, 1984;

Accepted December 11, 1984

\footnotetext{
${ }^{1}$ This work was supported by United States Public Health Service Grant DA 02148. The expert technical assistance of Jean Floyd and the helpful assistance of Drs. Virginia Seybold and Martin Wessendorf during the prcparation of this manuscript is gratefully acknowledged.

${ }^{2}$ To whom correspondence should be addressed.
}

Recently, a novel 36-amino acid peptide with potent biological activity (Lundberg et al., 1982; Agnati et al., 1983; Fuxe et al., 1983; Stjernquist et al., 1983), neuropeptide Y (NPY; Tatemoto et al., 1982; Tatemoto, 1982), was isolated from porcine brain. In subsequent studies, NPY-like immunoreactivity was shown to be present in regions throughout the rat nervous system (Allen et al., 1983; Guy et al., 1983; Hökfelt et al., 1983; O'Donohue et al., 1983; Emson and De Quidt, 1984; Everitt et al., 1984; Lundberg et al., 1984); including several that are involved in autonomic regulation. Furthermore, an NPY-like immunoreactive substance from rat brain extracts has been shown to elute in the same position as pure porcine NPY after high pressure liquid chromatographic fractionation (Allen et al., 1983; Lundberg et al., 1984). Recently, Emson and De Quidt (1984) noted that NPY-like immunoreactive cells were present in the substantia gelatinosa and sacral regions of the rat spinal cord, and Gibson et al. (1984) described the distribution of NPY-like immunoreactive fibers in the spinal cord of several species. There have been no studies, however, in which the distribution of NPY-like immunoreactive cells in the sixth lumbar (L6) and first sacral (S1) spinal cord segments of the rat has been described in detail. These segments are of particular interest because they contain the neurons of origin of parasympathetic preganglionic fibers that innervate the pelvic viscera. Thus, a portion of the present study describes the distribution and assesses the number of NPY-like immunoreactive cells in L6 and S1 of the rat spinal cord. In addition, it describes in greater detail the distribution and density of NPY-like immunoreactive fibers in these segments.

The present study was also aimed at comparing the distribution of NPY-like immunoreactivity to the distribution of FMRF-amide-like immunoreactivity in L6 and S1 of rat spinal cord. In a previous study (Sasek et al., 1984) we described the distribution of FMRF-amidelike immunoreactivity in these spinal cord segments and hypothesized that the immunoreactivity seen with this antiserum was due to recognition of NPY or its precursor by the FMRF-amide antiserum. We based this hypothesis on several pieces of evidence, most notably the absence of bona fide FMRF-amide in the central nervous system of the rat (Bishop et al., 1983), the cross-reactivity of IMRFamide antiserum with synthetic NPY (Sasek et al., 1984), and the presence of NPY in the rat central nervous system (Allen et al., 1983; Lundberg et al., 1984). Thus, we have attempted to provide further support for this hypothesis by determining whether the distributions of NPY and FMRF amide like immunoreactivities in L6 and S1 were similar and whether NPY-and FMRF-amide-like immunoreactivities were localized in the same neurons of the dorsal gray commissure (DGC) in L6 and S1 of the rat spinal cord.

\section{Materials and Methods}

Surgery. Twenty-two male Sprague-Dawley rats (280 to $340 \mathrm{gm}$ ), anesthetized with chloral hydrate $(350 \mathrm{mg} / \mathrm{kg})$, were implanted with chronic intrathecal cannulae to the level of approximately L6/S1 $(8.5 \mathrm{~cm})$ according 10 the method of Yaksh and Rudy (1976). The animals were allowed to recover 
from the anesthesia, and any animals showing signs of hindlimb paralysis resulting from the carnulation were discarded. To visualize immunohisto chemically peptide-containing neurons, colchicine ( 25 to $50 \mu \mathrm{g} / 10$ to $20 \mu$; Sigma Chemical $\mathrm{Co}$.) in $0.9 \%$ saline was administered via the cannulae to the lumbosacral spinal level at 0 and $24 \mathrm{hr}$. All animals used in the present study received colchicine.

Tissue preparation. At $48 \mathrm{hr}$ anesthetized animals were perfused transcardially with calcium-free Tyrode's solution equilibrated with $95 \% \mathrm{O}_{2} /$ $5 \% \mathrm{CO}_{2}$ followed either by $4 \%$ paraformaldehyde in $0.1 \mathrm{M}$ phosphate buffer $(\mathrm{pH} 6.5 ; 200 \mathrm{ml})$ and then $4 \%$ paraformaldehyde in $0.1 \mathrm{M}$ borate buffer $(\mathrm{pH}$ 9.2; $500 \mathrm{ml}$; Berod et al., 1981), or by $2 \%$ paraformaldehyde and $15 \%$ picric acid in $0.1 \mathrm{M}$ phosphate buffer (Stefanini et al., 1967). L6 and S1 were dissected from the animals and allowed to postfix for approximately $2 \mathrm{hr}$. At this point tissues were inspected with a dissecting microscope, and they showed no signs of damage due to cannula insertion or drug treatment. The tissue was then transferred to $5 \%$ sucrose in $0.1 \mathrm{M}$ phosphate buffer $(\mathrm{pH}$ 7.2) and stored until sectioning.

Immunohistochemistry. Tissue was processed according to either the peroxidase-antiperoxidase technique of Sternberger (1979) for distribution studies, or the immunofluorescence technique of Coons (1958) as modified by Hökfelt and Goldstein (1975) for co-localization studies (Hökfelt et al., 1977). Those cord segments to be processed according to the peroxidaseantiperoxidase technique were cut at $50 \mu \mathrm{m}$ either in a transverse or a horizontal plane on a vibrating microtome and placed in a well containing phosphate-buffered saline (PBS). The sections were then incubated for 10 min in phenylhydrazine hydrochloride $(100 \mu \mathrm{g} / \mathrm{ml}$ of PBS; Eastman Organic Chemicals) to inactivale endogenous peroxidase activity (Straus, 1972), rinsed several times in PBS, and incubated at $4^{\circ} \mathrm{C}$ overnight in antiserum to NPY (1/1000 dilution). The generation and characterization of the NPY antiserum have been described elsewhere (Lundberg et al., 1984). All antisera used in this study were diluted with $0.3 \%$ Triton X-100 in PBS.

The next day, after rinsing in PBS, the sections were sequentially incubated in sheep anti-rabbit IgG (1/300 dilution for $1 \mathrm{hr}$; Antibodies Inc.), two PBS rinses (15 min each), and rabbit peroxidase-antiperoxidase (1/500 dilution for $1 \mathrm{hr}$; Cooper Biomedical) at room temperature. After further rinsing, the sections in each well were reacted with approximately $1 \mathrm{ml}$ of $3,3^{\prime}$-diaminobenzidine tetrahydrochloride $(50 \mu \mathrm{g} / \mathrm{ml}$ of $0.05 \mathrm{M}$ Tris-buffered $0.9 \%$ saline, $\mathrm{pH}$ 7.6; Sigma and $0.3 \% \mathrm{H}_{2} \mathrm{O}_{2}(330 \mathrm{nl} / \mathrm{ml}$ of diaminobenzidine tetrahydrochloride) for 5 to $10 \mathrm{~min}$. An additional $5 \mu$ of $0.3 \% \mathrm{H}_{2} \mathrm{O}_{2}$ was added to each incubation well and sections were incubated for another 5 to $10 \mathrm{~min}$. The reaction was halted by rinsing with Tris-buffered saline. The sections were then rinsed several times in Tris buffer, mounted on gelatin-coated slides, dehydrated, cleared, and coverslipped. Sections were viewed and photographed on an Olympus microscope, model $\mathrm{BH} 2$.

NPY-like immunoreactive cells were found in most regions of the spinal cord. The sacral parasympathetic nucleus (SPN) and DGC were identified as previously described (Sasek et al., 1984) and the boundries of the substantia gelatinosa were identified by using darkfield microscopy. Neurons which were immunoreactive for NPY were counted in randomly selected sections from L6 and $\mathrm{S} 1$ from seven animals. Neurons were identified by the presence of either a nucleus or nerve processes. The mean number of cells per nucleus per section and standard error were calculated, and a MannWhitney $U$ test was used to determine whether there was a significant difference between the number of immunoreactive cells in $L 6$ and $S 1$ for each region. The numbers of NPY-like immunoreactive cells in the DGC and SPN were compared with data previously obtained with an antiserum to FMRF-amide (Sasek et al., 1984) using a Mann-Whitney $U$ test. The densities of immunoreactive fibers were rated according to the following scheme: very dense $(++++)$, dense $(+++)$, moderate $(++)$, and sparse $(t)$. Levels of density are illustrated in Figure 4 , $a$ and $b$ (very dense, dorsolateral nucleus; sparse, ventral horn) and Figure 1a (dense, substantia gelatinsoa; moderate, nucleus proprius). The density and distribution of NPY- and FMRF-amide-like immunoreactive fibers were compared using tissues from a previous study of the distribution of FMRF-amide (Sasek et al., 1984).

To determine whether NPY-and FMRF-amide-like immunoreactivities were localized in the same neurons, experiments were carried out in which tissue was processed for immunofluorescence. In these experiments, identified cord segments were cut serially at $5 \mu \mathrm{m}$ in a transverse plane on a cryostat and mounted on gelatin-coated slides. After rehydrating, alternate sections were incubated overnight at $4^{\circ} \mathrm{C}$ with rabbit antisera to either FMRF-amide (1/100 dilution; rabbit 246a) or NPY (1/100 dilution). The antiserum to FMRFamide was generated in our laboratory, and its generation and characterization have been described previously (Sasek et al., 1984). The next day the sections were rinsed with PBS and incubated for $1 \mathrm{hr}$ at room temperature with fluorescein-labeled goat anti-rabbit lgG (1/8 dilution; Antibodies Inc). The sections were rinsed and then counterstained with ethidium bromide $(1 \mu \mathrm{g} /$ ml of PBS, Sigma; Schmued et al., 1981), a fluorescent Nissl stain. After rinsing, the slides were coverslipped with PBS/glycerin (3/1). Sections were viewed and photographed on a Zeiss fluorescence microscope equipped with epi-illumination.

The number of cells present in each section was recorded, and each section was photographed. Then the coverslips were removed with PBS and the sections were restained with the other primary antiserum without eluting the first antiserum (i.e., tissue first stained with anti-FMRF-amide was then stained for NPY, and tissue first stained with anti-NPY was then stained for FMRF-amide). The number of cells per section was then recounted and the sections were rephotographed (Hökfelt et al., 1977). The data were analyzed and compared using a Mann-Whitney $U$ test and the photographs. By means of this method a numerical assessment of coexistence can be obtained. If coexistence is complete, no new cells will be detected after restaining. If there is no coexistence, the number of cells present after restaining will equal the sum of the number of cells seen with each antiserum. To determine whether one can sequentially stain two antigens, sections were immunostained with anti-vasoactive intestinal polypeptide, anti-substance $\mathrm{P}$, or antisomatostatin, and the number of immunostained cells was counted. The sections were then restained with anti-FMRF-amide or anti-methionine enkephalin. An increase in the number of immunoreactive cells was identified with both antisera; thus, it was concluded that processing tissue for immunofluorescence does not prevent visualization of additional immunoreactive substances.

Specificity studies. As a control, NPY antiserum at its working dilution was incubated with synthetic porcine NPY $(10 \mu \mathrm{g} / \mathrm{ml}$; Peninsula Laboratories $)$, and the ability of the antiserum to stain tissue was tested. Incubation of the NPY antiserum with synthetic NPY abolished all immunostaining.

As an additional control, the technique of Larsson (1981) was used to test the ability of the NPY antiserum to recognize heterologous peptides. Briefly, this technique consists of applying small volumes of peptide solutions to Whatman no. 1 filter paper, fixing them to the paper with paraformaldehyde vapors in vacuo, and processing the papers according to the peroxidaseantiperoxidase technique of Sternberger (1979). NPY antiserum was tested for its ability to recognize NPY, peptide YY (Bachem), FMRF-amide (Bachem), avian pancreatic polypeptide (Bachem), somatostatin (Sigma), substance P (Sigma), neurotensin (Peninsula), vasoactive intestinal polypeptide (Sigma), cholecystokinin octapeptide (Vega Biochemicals), methionine and leucine enkaphalin (Sigma), dynorphin 1-8 (Peninsula), neurophysins I and II (generously donated by Dr. Virginia Seybold), bombesin (Sigma), and oxytocin (Bachem). Using this technique it was found that the NPY antiserum reacted with the homologous antigen and with peptide $Y Y$; however, since peptide YY does not appear to be present in the spinal cord (Hökfelt et al., 1983; Lundberg et al., 1984; our unpublished observations), the NPY-like immunoreactivity seen in the present study is most probably not due to crossreactivity with peptide $Y Y$. The antiserum did not cross-react with any other of the peptides.

\section{Results}

\section{Distribution of NPY}

The distribution of NPY-like immunoreactive cells and fibers was similar in L6 and S1; thus, the descriptions that follow will be for both segments, unless otherwise specified. Table I summarizes the number of NPY-like immunoreactive cells in each segment and rcgion and the distribution and density of immunoreactive fibers. It should be noted that, although colchicine has been found in some instances to decrease the density of immunoreactive fibers, preliminary studies in our laboratory indicate that there is little or no difference in the density of NPY-or FMRF-amide-like immunoreactive fibers in colchicine-treated animals as compared to nontreated animals. However, it is possible that some undetected alterations in fiber density or pattern occurred as a result of colchicine treatment; therefore, in comparing the distribution of FMRF-amide- and NPYlike immunoreactivities, colchicine-treated tissue was used for both antisera.

SPN. The SPN contained a dense plexus of NPY-like immunoreactive fibers (Fig. 1A, Table 1 ) and an occasional round or triangular NPY-like immunoreactive cell (Fig. 2A, Table I). The SPN in S1 was found to contain slightly fewer immunoreactive cells per section than did the SPN in L6. A prominent band of long, beaded immunoreactive fibers extended between the plexus of immunoreactive fibers in 
TABLE I

Summary of the distribution of NPY-like immunoreactivity in the sixth lumbar and first sacral spinal cord segments

\begin{tabular}{|c|c|c|c|}
\hline \multirow{2}{*}{ Region } & \multicolumn{2}{|c|}{ CELLS/REGION/SECTION ${ }^{a}$} & \multirow{2}{*}{ Fibers $^{\circ}$} \\
\hline & $L 6$ & S1 & \\
\hline Sacral parasympathetic nucleus ${ }^{c}$ & $0.5 \pm 0.0(46)$ & $0.4 \pm 0.0(40)$ & +++ \\
\hline Substantia gelatinosa and marginal zone ${ }^{c}$ & $3.4 \pm 0.1(18)$ & $1.9 \pm 0.1(14)$ & +++ \\
\hline Nucleus proprius & $0.8 \pm 0.1(18)$ & $0.3 \pm 0.0(14)$ & ++ \\
\hline Ventral horn & $0.3 \pm 0.0(44)$ & $0.2 \pm 0.0(24)$ & + \\
\hline Dorsomedial nucleus & $0.0(14)$ & & $++^{a}$ \\
\hline Lateral spinal nucleus & $0.9 \pm 0.2(20)$ & $0.7 \pm 0.2(20)$ & ++ \\
\hline Lateral funiculus & $0.0(15)$ & $0.0(17)$ & ++ \\
\hline Ventrolateral funiculus & $0.0(15)$ & $0.0(17)$ & $+++^{d}$ \\
\hline
\end{tabular}

${ }^{a}$ Values represent mean \pm SEM; numbers in parentheses are the number of cells studied.

${ }^{b}$ Fiber density was rated as follows: ++++ , very dense; +++ , dense; ++ , moderate; + , sparse.

${ }^{c}$ Regions in which a significant difference $(p<0.05)$ was seen between the number of immunoreactive cells in L6 and S1

${ }^{d}$ Represents fiber density in L6.

the SPN and a plexus of immunoreactive fibers present in the DGC (Figs. $1 A$ and $2 C$ ). In some sections bipolar imrmunoreactive cells with medially and laterally directed processes were located along this band of fibers (Fig. 2C).

DGC. Numerous round, triangular, or spindle-shaped NPY-like immunostained cells were present in the DGC (Figs. $1 A$ and $2 C$, Table I). Long beaded axons from some of the more laterally situated immunoreactive cells could be followed through the intermediate gray and into the SPN. In horizontal sections (Fig. 2C) the immunoreactive cells in the DGC were seen to be organized in clusters the centers of which were separated by a variable distance of 200 to $300 \mu \mathrm{m}$. The clusters of cells were interconnected by bundles of immunoreactive fibers.

The immunoreactive cells in the DGC were surrounded by a dense plexus of NPY-like immunoreactive fibers (Fig. 1A, Table I). This plexus merged with the band of immunoreactive fibers that extended between the DGC and SPN (Fig. 1a). Additionally, NPY-like immunoreactivity was seen in longitudinally oriented fiber bundles located dorsal and ventral to the central canal (Figs. $1 A$ and $2 B$ ). The dorsal fiber bundle was present in most sections through $S 1$ but was absent in many through L6. The ventral bundle, which was less dense than the dorsal bundle, was not present in many sections through both $L 6$ and $S 1$. In those sections in which a distinct dorsal or ventral bundle was not present, it was replaced by a diffuse plexus of immunoreactive fibers.

Numerous immunoreactive fibers were also present along the sides of the central canal (Fig. 2B). These fibers, which ran in a dorsoventral direction, merged dorsally with the dorsal bundle and ventrally with the ventral bundle. In some sections an additional dorsoventrally oriented immunoreactive fiber bundle was located between the DGC and the dorsal longitudinal bundle.

Dorsal horn. Scattered, round NPY-like immunoreactive cells were located throughout the dorsal horn (Figs. $1 A$ and $3 A$ ). The greatest numbers of immunoreactive cells, however, were present in the substantia gelatinosa and the marginal zone ( whereas fewer immunoreactive cells were present in the nucleus proprius (Fig. $3 A$; Table I). A significantly greater number of immunoreactive cells was present in the substantia gelatinosa and marginal zone of L6 than in the same regions in S1.

Dense plexuses of punctate NPY-like immunoreactivity were present in the marginal zone and outer substantia gelatinosa of the dorsal horn (Figs. $1 A$ and $3, A$ and $B$; Table I). In some sections horizontally oriented, varicose immunoreactive fibers formed a cap over the punctate immunoreactivity in the marginal zone and substantia gelatinosa. A moderate number of immunoreactive fibers was present in nucleus proprius (Figs. $1 A$ and $3 A$ ). Many of these were long, beaded fibers that merged with the immunoreactive fibers in the marginal zone and substantia gelatinosa and had orientations perpendicular to these regions (Fig. 3A). In addition, clusters of irnrmunoreactive fibers were often present in the lateral part of nucleus proprius. The perpendicularly oriented fibers often appeared to terminate in these clusters of fibers.

Long, varicose NPY-like immunoreactive fibers were also identified medially in the dorsal horn along the lateral edge of the dorsal funiculus (Fig. 1A). These fibers extended between the medial edge of the substantia gelatinosa and the DGC, and they merged with the immunoreactive fiber plexus located in the DGC.

In some sections a sparse bundle of NPY-like immunoreactive fibers extended between the lateral edge of the substantia gelatinosa and the DGC. An occasional bipolar immunoreactive neuron was located along these fibers. The processes of the bipolar neurons followed the course of the fibers. An additional, larger NPY-like immunoreactive fiber bundle that extended through the lateral funiculus from the lateral part of the substantia gelatinosa to the SPN was also present in some sections.

Ventral horn. Only an occasional round or triangular NPY-like immunoreactive cell was present in the ventral horn (Table I). These cells, which were smaller than the large ventral horn motoneurons, were not localized to a specific part of the ventral horn but were scattered throughout its extent.

Although only a sparse distribution of long varicose NPY-like immunoreactive fibers was present in most of the ventral horn (Fig. $4, A$ and $B$; Table I), a very dense accumulation of immunoreactive fibers was seen in the dorsolateral nucleus of the ventral horn (Fig. $4, A$ and $B$; Table I), and a moderate distribution of fibers was present in the dorsomedial nucleus of the ventral horn (Fig. 4A, Table I). Both of these nuclei contain neurons that innervate pelvic muscles, and the dorsolateral nucleus is considered to be the rat homologue of Onuf's nucleus. Neither nucleus is present in S1 (Schroder, 1980). Immunoreactive fiber bundles that extended between the dorsolateral and dorsomedial nuclei and between the dorsolateral nucleus and the SPN (Fig. 4B) were seen in some sections. The immunoreactive fiber plexuses in both the dorsolateral and dorsomedial nuclei were only present in sections taken through L6.

White matter. A moderate distribution of immunoreactive fibers and an occasional round or triangular immunoreactive cell was localized in the lateral spinal nucleus (Giesler and Elde, 1985) of the dorsolateral funiculus (Fig. 4B, Table I). A moderate plexus of fibers was also present just lateral to the SPN in the lateral funiculus, and in many sections immunoreactive fibers could be followed from the SPN into this plexus.

In sections taken through L6, long, beaded immunoreactive fibers were scattered throughout the ventral funiculus (Table I). Similar fibers were present in sections through $\mathrm{S1}$; however, their distribution was extremely sparse. In sections through L6, dense bundles of 

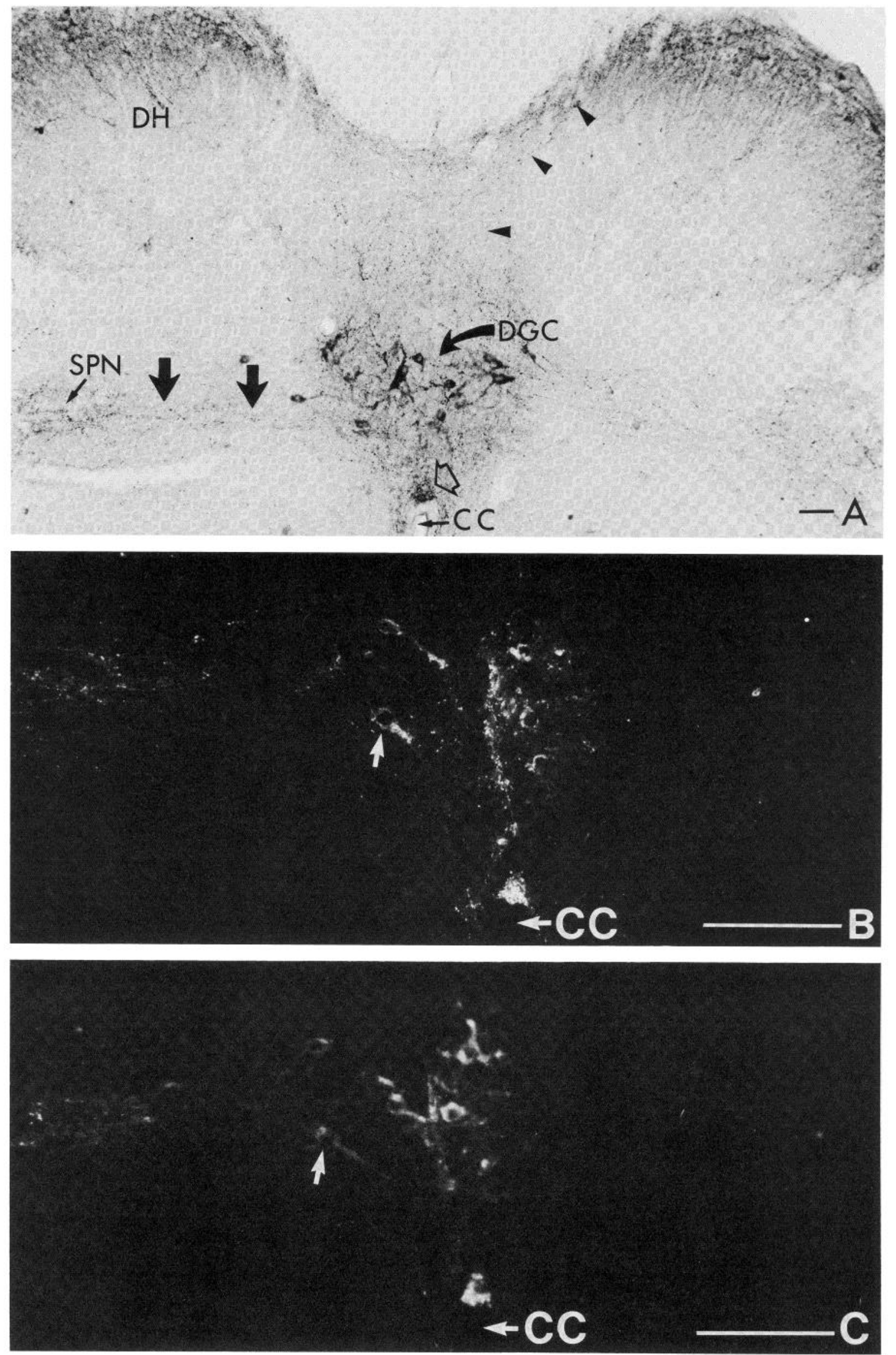

Figure 1. A, Photomicrograph of a transverse section through L6 of rat spinal cord after incubation with NPY antiserum. Immunostaining in the SPN, DGC, dorsal horn $(D H)$, and intermediate gray can be seen. Arrowheads indicate immunostained fibers that extend between the substantia gelatinosa and the DGC. Double solid arrows indicate immunostained fibers that extend between the DGC and SPN. The open arrow indicates the longitudinally oriented immunoreactive fiber bundle dorsal to the central canal $(C C) . B$ and $C$, Serial transverse sections through the dorsal gray commissure in $S 1$ showing the similar distribution of NPY- $(B)$ and FMRF-amide-like $(C)$ immunoreactivities. Arrows indicate an example of a neuron, found in both sections, that contains NPY- and FMRF-amide-like immunoreactivities. Bars $=50 \mu \mathrm{m}$. 

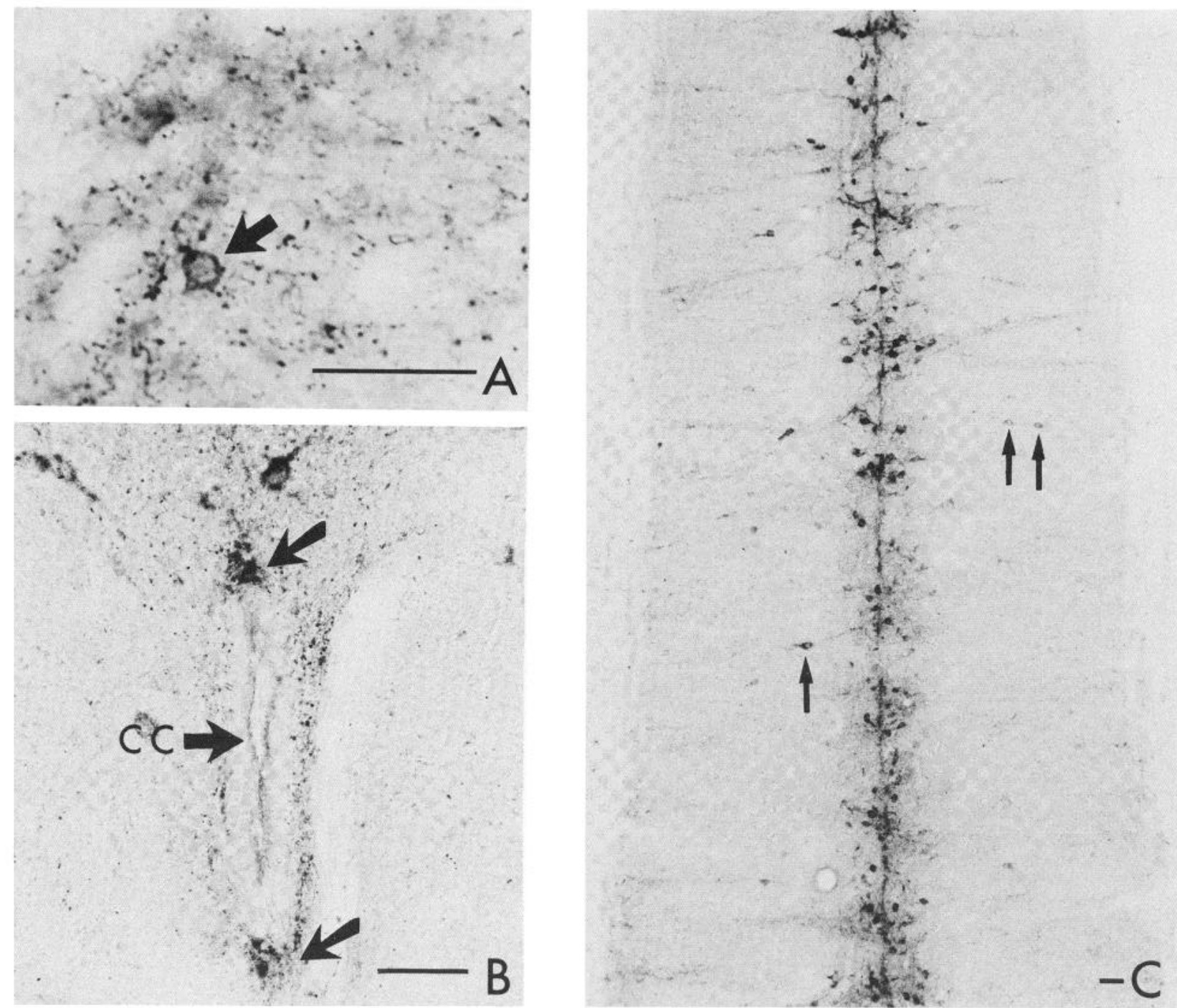

Figure 2. Photomicrographs of sections through $L 6(A)$ and $S 1(B$ and $C)$ of rat spinal cord after incubation with NPY antiserum. $A$, High magnification transverse section showing an immunoreactive cell (arrow) in the SPN. B, Transverse section showing immunoreactive fiber bundles (arrows) dorsal and ventral to the central canal (CC). C. Horizontal section through the DGC showing the arrangement of immunoreactive cells in the DGC, and the immunoreactive fiber bundles that extend between the DGC and the SPN. Arrows indicate bipolar immunoreactive cells in the intermediate gray. Bars $=50 \mu \mathrm{m}$.

immunoreactive fibers were seen in the ventrolateral funiculus (Fig. $4 B$, Table I). These immunoreactive bundles merged with the immunoreactive fibers in the dorsolateral nucleus of the ventral horn. No immunoreactive elements were observed in the dorsal funiculus.

\section{Comparison of NPY- and FMRF-amide-like immunoreactivities}

The pattern of immunostaining in L6 and S1 seen with the NPY antiserum was very similar to that previously described for the FMRFamide antiserum (Sasek et al., 1984), although there were some notable differences. In general, the distributions of NPY- and FMRFamide-like immunostained fibers in L6 and S1 were identical (Fig.1, $B$ and $C$ ). The density of NPY-like immunostaining in most regions, however, was greater by one level of fiber density than that of FMRF-amide-like immunostaining. For example, regions that had a dense distribution of immunoreactivity with the NPY antiserum had a moderate distribution with the FMRF-amide antiserum.

Whereas the fiber distribution appeared to be the same with the two antisera, the distribution of cells was not. NPY-like immunoreactive cells were present in the DGC, SPN, substantia gelatinosa, marginal zone, nucleus proprius, ventral horn, and lateral spinal nucleus. However, FMRF-amide immunoreactive cells were only present in the DGC and SPN. Furthermore, the SPN contained a significantly greater number of NPY-like immunoreactive cells than of FMRF-amide-like immunoreactive cells. The SPN, in L6 and S1, contained an average of $0.43 \pm 0.008(n=86)$ NPY-like immunoreactive cells/nucleus/section but only $0.06 \pm 0.06(n=32)$ FMRFamide-like immunoreactive cells/nucleus/section. There was no difference between the number of NPY- $(14.25 \pm 0.98, n ;=32)$ and FMRF-amide-like $(16.50 \pm 1.02, n=18)$ immunoreactive cells in the DGC. There was also no difference in the shape and distribution of NPY- and FMRF-amide-like immunoreactive cells in either the DGC or SPN.

\section{Co-localization of NPY- and FMRF-amide-like immunoreactivities}

NPY- and FMRF-amide-like immunoreactivities were present in the same cells in the DGC, and the co-localization appeared to be complete. Figure 5 shows adjacent $5-\mu \mathrm{m}$ sections stained with antiNPY (Fig. 5, $A$ and C) or anti-FMRF-amide (Fig. 5B). The same two immunostained neurons (Fig. 5 , arrows) can be identified in all three micrographs (Fig. 5, $A$ to $C$ ), indicating that NPY-and FMRF-amidelike immunoreactivities were localized to the same neurons. By comparing micrographs of several adjacent sections immunostained with anti-NPY or anti-FMRF-amide, it was determined that virtually every cell in the DGC that contained NPY-like immunoreactivity also contained FMRF-amide-like immunoreactivity. To further verify this and to quantitatively define the extent of co-localization, sections 

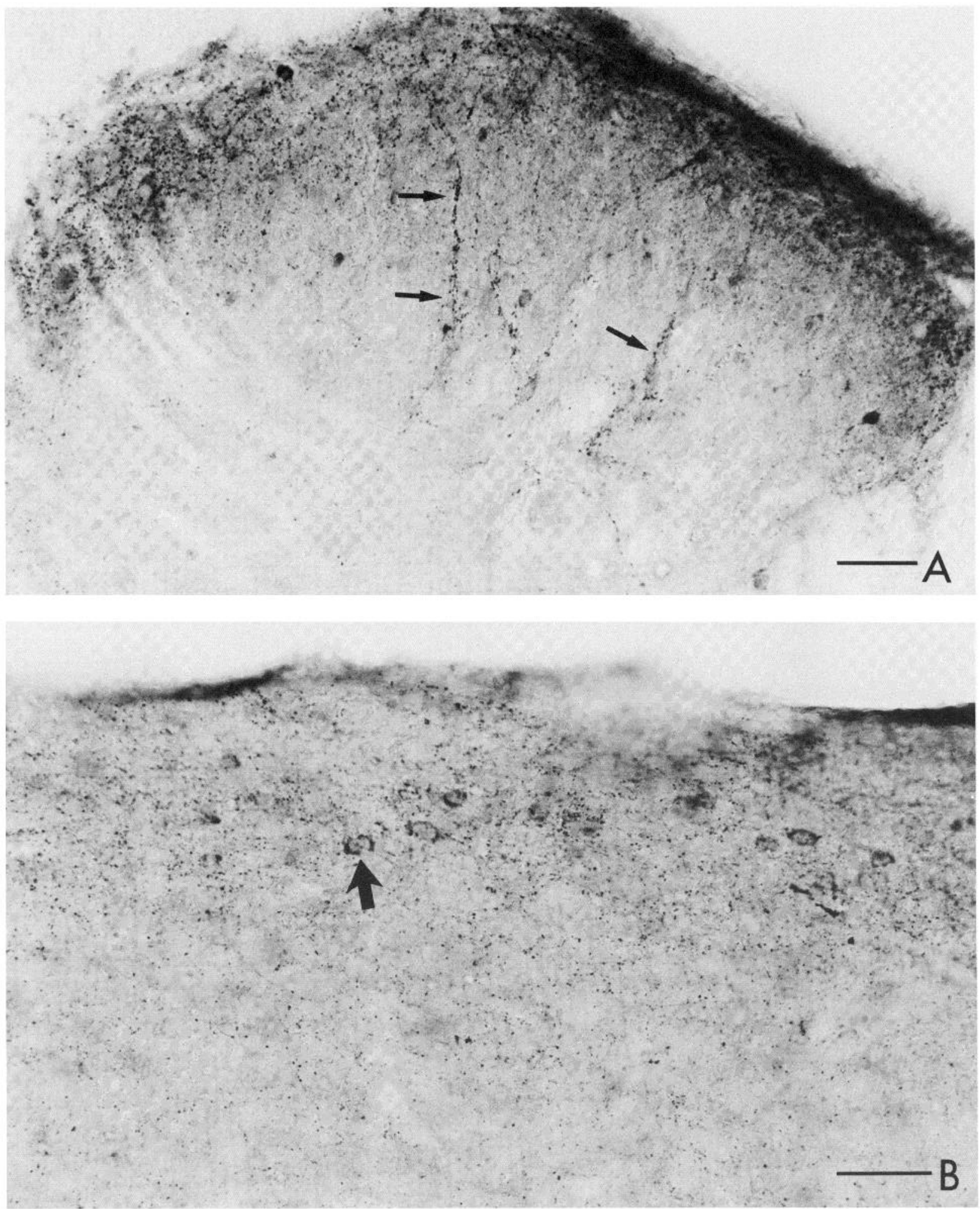

Figure 3. High power photomicrographs of sections stained with NPY antiserum. $A$, Transverse section through the dorsal horn in L6; $B$, horizontal section through the substantia gelatinosa in S1. The arrows in $A$ indicate perpendicularly oriented fibers extending between the substantia gelatinosa and the nucleus proprius. The arrow in $B$ points to an example of an immunoreactive cell. The punctate nature of the immunoreactivity is especially evident in $B$. Bars $=50$ $\mu \mathrm{m}$.

stained for FMRF-amide were restained for NPY and vice versa. The number of immunostained cells found after restaining was then compared to the number found before restaining. It was found that sections immunostained for FMRF-amide contained $2.21 \pm 0.04$ cells $/ 5-\mu \mathrm{m}$ section prior to restaining and $2.21 \pm 0.04$ cells $/ 5-\mu \mathrm{m}$ section after restaining with antiserum to NPY. Similarly, in sections immunostained with NPY antiserum, $2.29 \pm 0.05$ cells $/ 5-\mu \mathrm{m}$ section were found prior to restaining and $2.29 \pm 0.05$ cells $/ 5-\mu \mathrm{m}$ section were found after restaining with FMRF-amide antiserum. There was no difference in the number of immunoreactive cells per section 

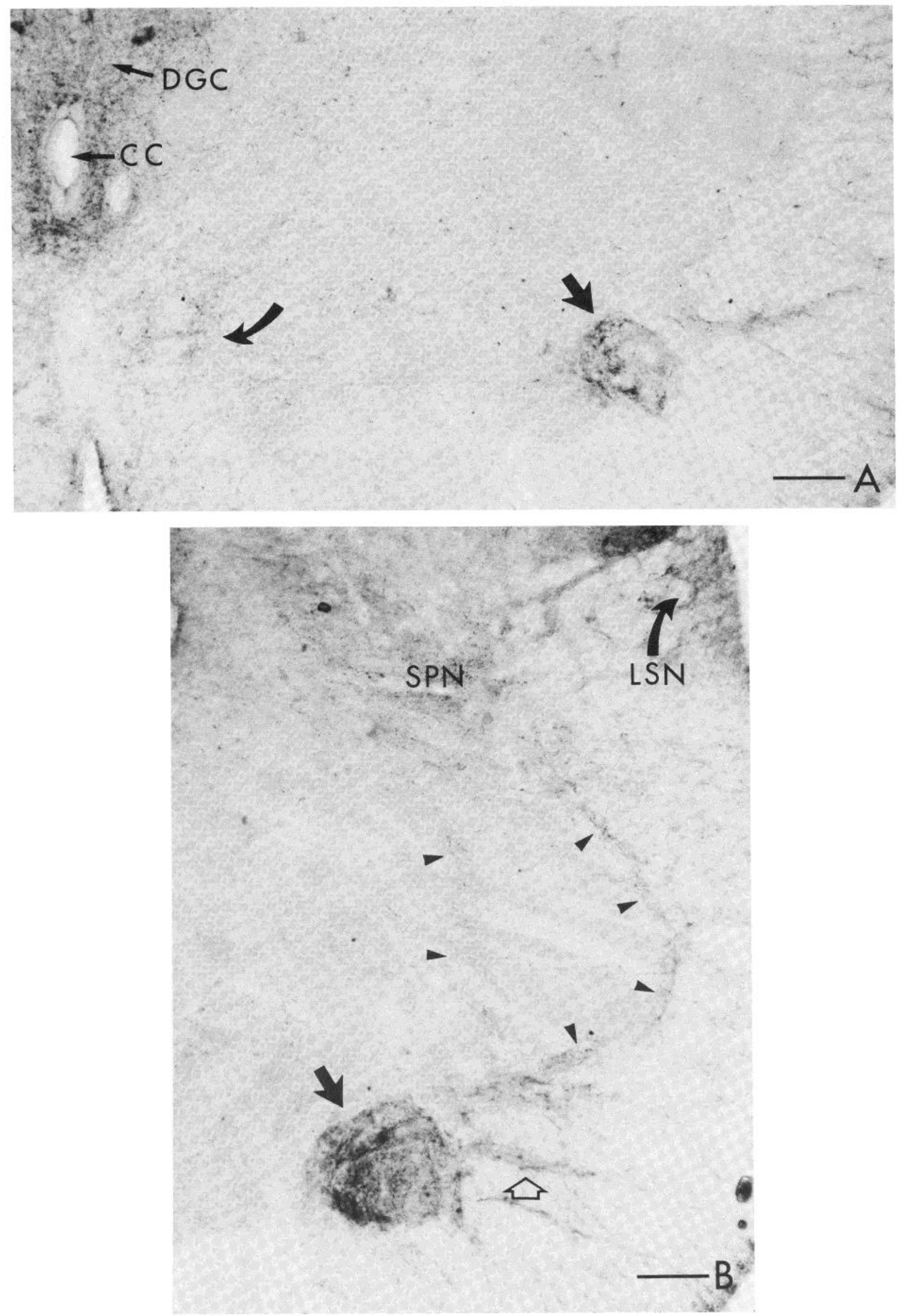

Figure 4. Photomicrographs of transverse sections through L6 of rat spinal cord showing the dorsolateral nucleus (straight, solid, thick arrows in $A$ and $B$ ) and the dorsomedial nucleus (curved, solid, thick arrow in $A$ ) after immunostaining with NPY antiserum. Arrowheads in $B$ indicate immunoreactive bundles that extend between the SPN and dorsolateral nucleus. The open arrow in $B$ indicates fibers in the ventrolateral funiculus that merge with immunoreactive fibers in the dorsolateral nucleus. The lateral spinal nucleus $(L S N)$ can be seen in the upper right corner of $B$ (arrow). Bars $=50 \mu \mathrm{m}$. 

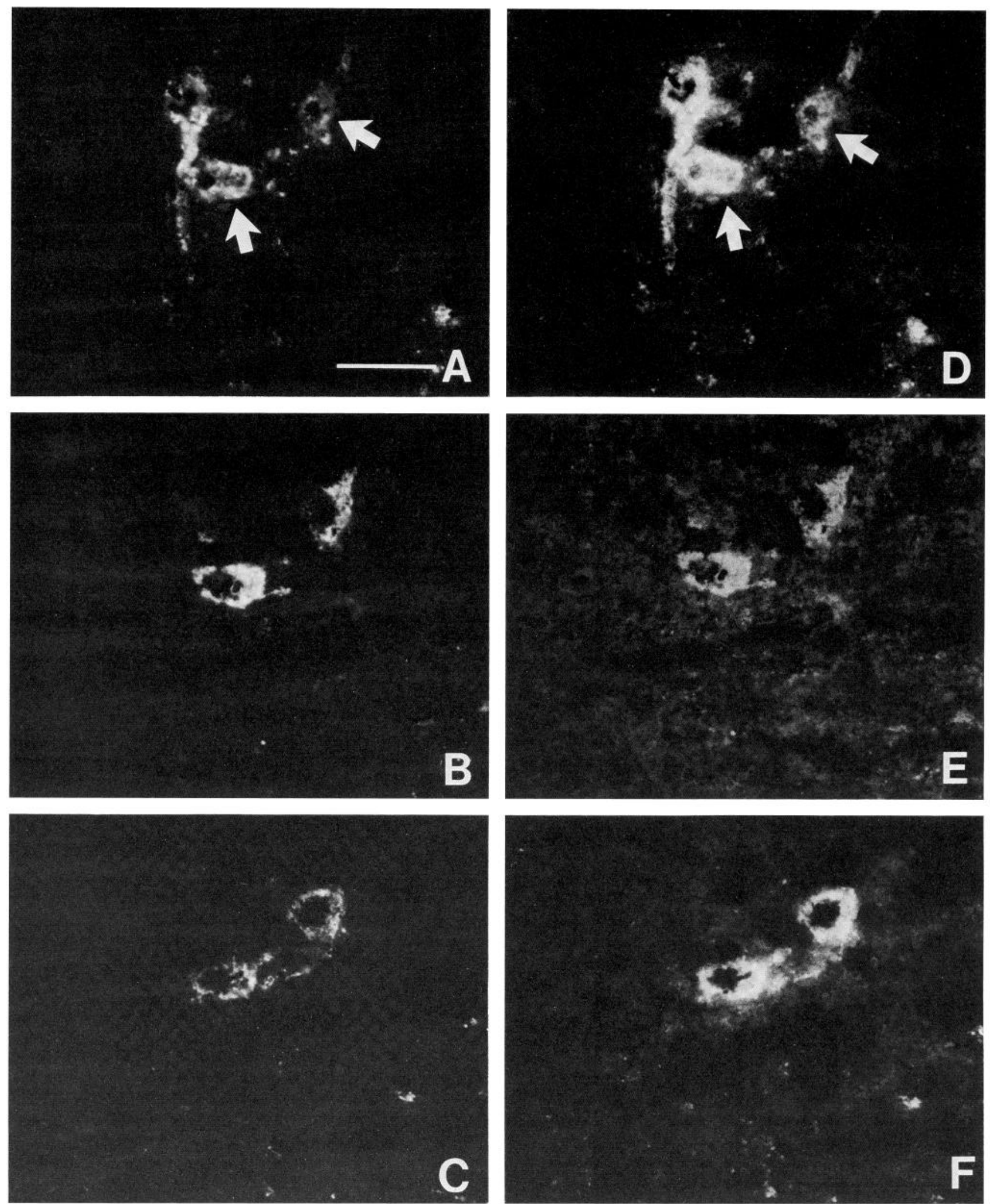

Figure 5. Immunofluorescence photomicrographs of serial 5- $\mu \mathrm{m}$ transverse sections through S1 after staining with NPY antiserum (A and $C$ ) or FMRFamide antiserum $(B)$. $D$ to $F$ show the same sections as $A$ to $C$ after restaining with FMRF-amide $(A$ and $C)$ or NPY $(B)$. Note that the same two immunostained cells can be followed through all three sections (arrows in $A$ ) and that no additional immunostained cells are seen after restaining with opposite antiserum $(D$ to $F)$. Bar $=25 \mu \mathrm{m}$; all micrographs are of equal magnification. 
before and after restaining. Furthermore, in neither case were any additional cells found on photomicrographs after restaining (Fig. 5 , cf. $A$ to $C$ with $D$ to $F$ ). These results clearly demonstrate that NPY. and FMRF-amide-like immunoreactivities are localized in the same neurons in the DGC of $L 6$ and S1.

\section{Discussion}

The results of the present studies demonstrate the presence of an NPY-like immunoreactive substance in L6 and S1 of the rat spinal cord. They extend the work of Emson and De Quidt (1984) and Gibson et al. (1984) by providing a detailed description of NPY-like immunoreactivity in $\mathrm{L} 6$ and $\mathrm{S} 1$ and by quantitying the number of immunoreactive cells in these segments. $L 6$ and $S 1$ are of particular interest because they contain the cell bodies of the parasympathetic preganglionic neurons.

It is not clear what functions are mediated by the NPY-like immunoreactive elements in each of these regions. The distribution of NPY-like immunoreactivity in L6 and S1, however, suggests that an NPY-like peptide may be involved in several functions, including regulation of pelvic viscera, transmission and processing of primary afferent sensory information, and motor regulation of pelvic musculature.

NPY-like immunoreactive cells and fibers in both the SPN and DGC may be involved in the regulation of pelvic viscera. The NPY. like immunoreactive cells in the SPN are similar in shape and location to those of parasympathetic preganglionic neurons in the rat as described by Hancock and Peveto (1979) and Nadelhaft and Booth (1982). Preganglionic cells are round, triangular, or spindle shaped. The majority of preganglionic cells are located in the SPN, but occasional cells are found more medially in the intermediate gray. Thus, it is likely that at least some of the NPY immunostained neurons in the SPN are preganglionic neurons.

There is evidence to suggest that neurons in the DGC are also involved in autonomic regulation. Primary afferent fibers from pelvic viscera have been demonstrated to form terminal fields in the region in which these cells are localized (Morgan et al., 1981; Nadelhaft and Booth, 1982). In addition, in the present study, processes from NPY immunostained cells in the DGC were found to extend through the intermediate gray into the SPN. Thus, neurons in the DGC are in a prime location to act as interneurons in a reflex pathway between primary afferent and parasympathetic efferent neurons. They may therefore have an important function in integrating incoming visceral afferent information prior to relaying it to autonomic efferent neurons in the SPN. These neurons may also be important for relaying visceral afferent information to higher centers in the central nervous system and, therefore, for modulating descending input for the control of peivic viscera. Tract tracing studies have shown that cells in the DGC of L6 do project to the brainstem (Nahin et al., 1983); however, it is not known which if any peptides are contained in these projecting neurons.

The presence of NPY-like immunoreactivity in the dorsal horn suggests that any NPY-like peptide may be involved in the perception of sensory information. The marginal zone, substantia gelatinosa, and nucleus proprius are the sites of termination of primary afferent fibers (Light and Perl, 1979a, b; Ralston and Ralston, 1979). NPYlike immunoreactive terminals were identified in each of these regions, and the distribution was similar to that of other peptides that are known to be contained in primary afferent fibers (Seybold and Elde, 1980; Hunt et al., 1981), suggesting that some of the NPY-like immunoreactivity present in the dorsal horn may be primary afferent in origin. However, Gibson et al. (1984) detected no change in NPYlike immunoreactive fibers after dorsal rhizotomy at the cervical level, indicating that at cervical spinal cord levels NPY-like immunoreactive fibers are probably not primary afferent in origin. The distribution of NPY-like immunoreactivity is also similar to that of enkephalin, which is present in cells and fibers that are intrinsic to the spinal cord (Elde et al., 1976). Therefore, it is also possible that some or all of the NPY-like immunoreactivity in the dorsal horn, rather than having a primary afferent origin, represents the terminal fields of neurons that are intrinsic to the brain or spinal cord. Since NPY-like immunoreactive cells were also present in the dorsal horn, it is probable that many of the immunoreactive processes in the dorsal horn are from these neurons. Additional studies are necessary to determine the precise origin of these immunoreactive fibers. The NPY-like immunoreactive neurons in the dorsal horn may be interneurons that receive and modulate primary afferent input or, in the case of those immunoreactive cells in the nucleus proprius, cells of origin of ascending tracts such as the spinocervical or spinothalamic tracts.

An NPY-like peptide may also be involved in the regulation of somatic motor activity. NPY-like immunoreactive fibers were present in the dorsolateral and dorsomedial nuclei of the ventral horn. These nuclei contain motoneurons that innervate pelvic musculature (Schroder, 1980). No immunoreactive neurons were identified in either nucleus. The source of the immunoreactive fibers in the dorsolateral and dorsomedial nuclei is unknown, but their presence indicates that an NPY-like peptide may function to modulate the activity of neurons that innervate pelvic muscles.

Immunoreactive fiber bundles were identified between the dorsolateral nucleus and the SPN. Although voluntary, the activity of the pelvic musculature is intimately connected with that of the pelvic viscera. Thus, it might be speculated that the immunoreactive bundles consist of axon collaterals of parasympathetic, efferent, NPYcontaining neurons the function of which is to synchronize the activity of motoneurons that innervate pelvic muscles with the activity of pelvic viscera.

It should be noted that the present study was conducted using only male rats. Differences between male and female rats in the ventral horn nuclei that innervate the pelvic muscles have been described (Schroder, 1980). Therefore, it is possible that the distribution of NPY-like immunoreactivity in the ventral horn of female rats may be different from that of the male.

NPY-like immunoreactive cells and fibers were also identified in the lateral spinal nucleus. Although numerous other peptides have recently been identified in this region (Giesler and Elde, 1985), there is little known about its function. Retrograde tract-tracing studies utilizing horseradish peroxidase have demonstrated that some cells in the lateral spinal nucleus project to the mesencephaton (Menetrey et al., 1980, 1982; Giesler et al., 1981). It is not known, however, what substances are contained in these projecting neurons.

Comparison of NPY- and FMRF-amide-like immunoreactivities. FMRF-amide was first isolated in the clam ganglion by Price and Greenberg (1977). Subsequently, FMRF-amide antisera were shown to recognize a novel neuronal system throughout the mammalian CNS (Boer et al., 1980; Dockray et al., 1981; Weber et al., 1981; Sasek et al., 1983; Williams and Dockray, 1983). There has been much speculation as to the nature of the peptide or peptides recognized by these antisera. In a recent study we described the pattern of staining seen with the FMRF-amide antiserum in the rat spinal cord (Sasek et al., 1984) and hypothesized that the immunoreactivity was due to recognition of NPY by the FMRF-amide antisera. We based this hypothesis on the following pieces of evidence. The distribution of NPY-like immunoreactivity in the rat CNS appears to be nearly identical to that of FMRF-amide-like immunoreactivity (Hökfelt et al., 1983). The peptide FMRF-amide is not present in the rat CNS (Bishop et al., 1983), whereas NPY is present (Allen et al., 1983). The peptide recognized by anti-FMRF-amide in the mammalian CNS appears to be significantly larger than the tetrapeptide isolated from clam ganglion (Dockray et al., 1981). In addition, our FMRF-amide antisera recognize synthetic porcine NPY as well as or better than FMRF-amide in a model immunohistochemical system (Sasek et al., 1984).

In the present study we have attempted to provide additional support for this hypothesis by determining whether FMRF-amideand NPY-like immunoreactivities are localized in the same neurons in the DGC and whether they are similarly distributed in L6 and S1 of the rat spinal cord. It was found that NPY-and FMRF-amide-like 
immunoreactive fibers were distributed in a nearly identical pattern and there appeared to be complete co-localization of FMRF-amideand NPY-like immunoreactivities in neurons in the DGC. These results support the hypothesis that the peptide recognized by the FMRF. amide antiserum is indeed NPY or a related peptide.

There were, however, differences between the two antisera. The NPY antiserum generally stained fibers with a slightly greater intensity than did the FMRF-amide antiserum. In addition, NPY-like immunoreactive cells were identified in several regions in which FMRF-amide immunoreactive cells were not present. Since anti-FMRF-amide strongly recognizes NPY, these results suggest that some neurons process NPY-like peptides to a form unrecognized by anti-FMRFamide. Cross-reactivity tests have indicated that the FMRF-amide antiserum only recognizes the amidated carboxy-terminus of NPY. Any processing that changed or masked the carboxy-terminus or its amide group would prohibit the binding of the FMRF-amide antiserum. Furthermore, the FMRF-arnide aritiserum would be uriable to bind the precursor to the NPY-like peptide since most peptides that terminate in an amide group are synthesized as long molecules that are later cleaved and enzymatically amidated (Bradbury et al., 1982). Presumably the amidation of NPY occurs via this same mechanism.

In contrast, the NPY antiserurn probably contains several populations of antibodies that bind antigenic sites along the entire length of the NPY molecule. The NPY antiserum may, therefore, recognize the intact NPY molecule as well as forms that result from processing. Furthermore, the antiserum may recognize biosynthetic precursor molecules sirice recognition most probably does not depend on amidation.

Thus, the neurons identified immunohistochemically by both the FMRF-amide antiserum and the NPY antiserum most probably contain an NPY-like peptide with an amidated carboxy-terminus. Those neurons labeled by only the NPY antiserum may contain a form of NPY that has been processed in such a way as to make it unrecognizable by the FMRF-amide antiserum. These results suggest that several different NPY-like peptides exist in the rat CNS and that the processing and distribution of these peptides are not identical. Confirmation of these suggestions awaits further biochemical studies.

\section{References}

Agnati, L. F., K. Fuxe, F. Benfenati, N. Battistini, A. Harfstrand, K. Tatemoto T. Hökfelt, and V. Mutt (1983) Neuropeptide $Y$ in vitro selectively increases the number of $\alpha_{2}$-adrenergic binding sites in membranes of the medulla oblongata of the rat. Acta Physiol. Scand. 118: 293-295.

Allen, Y. S., T. E. Adrian, J. M. Allen, K. Tatemoto, T. J. Crow, S. R. Bloom, and J. M. Polak (1983) Neuropeptide $Y$ distribution in the rat brain. Science (NY) 221: 877-879.

Berod, A., B. K. Hartman, and J. F. Pujor (1981) Importance of fixation in immunohistochemistry: Use of formaldehyde solutions at variable $\mathrm{pH}$ for the localization of tyrosine hydroxylasc. J. Histochem. Cytochem. 29: 844 850 .

Bishop, J. F., W. W. Watson, J. Groome, and T. L. O'Donohue (1983) Distribution and characterization of FMRFamide-like peptides in rat brain and digestive system. Soc. Neurosci. Abstr. 9: 139.

Boer, H. H., L. P. C. Schot, J. A. Veenstra, and D. Reichelt (1980) Immunocytochemical identification of neural elements in the central nervous system of a snail, some insects, and a mammal, with an antiserum to the molluscan cardioexcitatory tetrapeptide FMRF-amide. Cell Tissue Res. 213: $21-27$

Bradbury, A. F., M. D. A. Finnie, and D. G. Smyth (1982) Mechanism of Cterminal amide formation by pituitary enzymes. Nature 298: 686-688.

Coons, A. H. (1958) Fluorescent antibody methods. In General Cytochemical Methods, J. R. Danielli, ed., pp. 399-422, Academic Press, Inc., New York.

Dockray, G. J., C. Vaillant, and R. G. Williams (1981) New vertebrate braingut peptide related to a molluscan neuropeptide and an opioid peptide. Nature 293: 656-657

Elde, R., T. Hökfelt, O. Johansson, and L. Terenius (1976) Immunohistochemical studies using antibodies to leucine-enkephalin: Initial observations on the nervous system of the rat. Neuroscience 1: 349-351.
Emson, P. C., and M. E. De Quidt (1984) NPY - A new member of the pancreatic polypeptide family. Trends Neurosci. 7: 31-35.

Everitt, B. J., T. Hökfelt, L. Terenius, K. Tatemoto, V. Mutt, and M. Goldstein (1984) Differential co-existence of neuropeptide $Y$ (NPY)-like immunoreactivity with catecholamines in the central nervous system of the rat. Neuroscience 11: 443-462.

Fuxe, K., L. F. Agnati, A. Harfstrand, I. Zini, K. Tatemoto, E. M. Pich, T. Hökfelt, V. Mutt, and L. Terenius (1983) Central administration of neuropeptide $Y$ induces hypotension bradypnea and EEG synchronization in the rat. Acta Physiol. Scand. 118: 189-192.

Gibson, S. J., J. M. Polak, J. M. Allen, T. E. Adrian, J. S. Kelly, and S. R. Bloom (1984) The distribution and origin of a novel brain peptide, neuropeptide $Y$, in the spinal cord of several mammals. J. Comp. Neurol. 227. 78-91.

Giesler, G. J., Jr., and R. P. Elde (1985) Immunocytochemical studies of the peptidergic content of fibers and terminals within the lateral spinal and lateral cervical nuclei. J. Neurosci., in press.

Giesler, G. J., Jr., H. R. Spiel, and W. D. Willis (1981) Organization of spinothalamic tract axons within the rat spinal cord. J. Comp. Neurol. 195 243-252.

Guy, J., Y. S. Allen, J. M. Polak, and G. Pelletier (1983) Immunocytochemical localization of neuropeptide $Y$ (NPY) in the rat brain. Soc. Neurosci. Abstr. 9: 291

I lancock, M. B., and C. A. Peveto (1979) Preganglionic neurons in the sacral spinal cord of the rat: An HRP study. Neurosci. Lett. 11: 1-5.

Hökfelt, T., K. Fuxe, and M. Goldstein (1975) Applications of immunohistochemistry to studies on monoamine cell systems with special references to nervous tissues. Ann. N. Y. Acad. Sci. 254: 407-432.

Hökfelt, T., L. G. Elfvin, R. Elde, M. Schultzberg, M. Goldstein, and R. Luft (1977) Occurrence of somatostatin-like immunoreactivity in some peripheral sympathetic noradrenergic neurons. Proc. Natl. Acad. Sci. U. S. A. 74: $3587-3591$.

Hökfelt, T., J. M. Lundberg, K. Tatemoto, V. Mutt, L. Terenius, J. Polak, S. Bloom, C. Sasek, R. Elde, and M. Goldstein (1983) Neuropeptide Y (NPY)and FMRF-amide neuropeptide-like immunoreactivities in catecholamine neurons of the rat medulla oblongata. Acta Physiol. Scand. 117: 315-318.

Hunt, S. P., J. S. Kelly, P. C. Emson, J. R. Kimmel, R. J. Miller, and J.-Y. Wu (1981) An ımmunohıstochemıcal study of neuronal populations containing neuropeptides or $\gamma$-aminobutyrate within the superficial layers of the rat dorsal horn. Neuroscience 6: 1883-1898.

Larsson, L. -1. (1981) A novel immunocytochemical model system for specificity and sensitivity screening of antisera against multiple antigens. J. Histochem. Cytochem. 29: 408-410.

Light, A. R., and E. R. Perl (1979a) Reexamination of the dorsal root projection to the spinal dorsal horn including observations on the differential termination of coarse and fine fibers. J. Comp. Neurol. 186: 117-132.

Light, A. R., and E. R. Perl (1979b) Spinal termination of functionally identified primary afferent neurons with slowly conducting myelinated fibers. J. Comp. Neurol. 186: 133-150.

Lundberg, J. M., L. Terenius, T. Hökfelt, C. R. Martling, K. Tatemoto, V. Mutt, J. Polak, S. Bloom, and M. Goldstein (1982) Neuropeptide Y (NPY)-like immunoreactivity in peripheral noradrenergic neurons and effects of NPY on sympathetic function. Acta Physiol. Scand. 116: 477-480.

Lundberg, J. M., L. Terenius, T. Hökfelt, and K. Tatemoto (1984) Comparative immunohistochemical and biochemical analysis of pancreatic polypeptidelike peptides with special reference to presence of neuropeptide $Y$ in central and peripheral neurons. J. Neurosci. 4: 2376-2386.

Menetrey, D., A. Chaouch, and J. M. Besson (1980) Location and properties of dorsal horn neurons at origin of spinoreticular tract in lumbar enlargement of the rat. J. Neurophysiol. 44: 862-8//

Menetrey, D., A. Chaouch, D. Binder, and J. M. Besson (1982) The origin of the spinomesencephalic tract in the rat: An anatomical study using the retrograde transport of horseradish peroxidase. J. Comp. Neurol. 206: 193-207.

Morgan, C., I. Nadelhaft, and W. C. deGroat (1981) The distribution of visceral primary afferents from the pelvic nerve to Lissauer's tract and the spinal gray matter and its relationship to the sacral parasympathetic nucleus. J. Comp. Neurol. 201: 415-440.

Nadelhaft, I., and A. M. Booth (1982) Preganglionic neurons and visceral afferent fibers in the rat pelvic nerve. Soc. Neurosci. Abstr. 8: 77.

Nahin, R. L., A. M. Madsen, and G. J. Giesler, Jr. (1983) Anatomical and physiological studies of the gray matter surrounding the spinal cord centra canal. J. Comp. Neurol. 220: 321-335.

O'Donohue, T. L., B. M. Chronwall, and D. A. DiMaggio (1983) Distribution 
of neuropeptide $Y$-like immunoreactivity in rat brain. Soc. Neurosci. Abstr. 9: 290.

Price, D. A., and M. J. Greenberg (1977) Structure of a molluscan cardioexcitatory neuropeptide. Science (N. Y.) 197: 670-671

Ralston, II. J., III, and D. D. Ralston (1979) The distribution of dorsal root axons in laminae I, II and III of the macaque spinal cord: A quantitative electron microscope study. J. Comp. Neurol, 184: 643-684.

Sasek, C. A., R. P. Elde, and V. S. Seybold (1983) Localization of FMRF $\mathrm{NH}_{2}$-like immunoreactivity in autonomic regions of the brainstem and spina cord of the rat. Soc. Neurosci. Abstr. 8: 809

Sasek, C. A., V. S. Seybold, and R. P. Elde (1984) The immunohistochemical localization of nine peptides in the sacral parasympathetic nucleus and dorsal gray commissure in rat spinal cord. Neuroscience 12: 855-887.

Schmued, L. C., L. W. Swanson, and P. E. Sawchenko (1981) Some fluorescent counterstains for neuroanatomical studies. Soc. Neurosci. Abstr. 7: 417

Schroder, H. D. (1980) Organization of the motoneurons innervating the pelvic muscles of the male rat. J. Comp. Neurol. 192: 567-587

Schroder. H. D. (1984) Somatostatin in the caudal spinal cord: An immunohistochemical study of the spinal centers involved in the innervation of pelvic organs. J. Comp. Neurol. 223: 400-414.

Seybold, V., and R. Elde (1980) Immunohistochemical studies of peptidergic neurons in the dorsal horn of the spinal cord. J. Histochem. Cytochem 28: $367-370$.
Stefanini, M., C. DeMartino, and L. Zamboni (1967) Fixation of ejaculated spermatozoa for clectron microscopy. Naturc 216: 173-174.

Sternberger, L. A. (1979) Immunocytochemistry, Prentice-Hall, Englewood Cliffs, NJ.

Stjernquist, M., P. Emson, C. Owman, N. -O. Sjoberg, F. Sundler, and $K$. Tatemoto (1983) Neuropeptide $Y$ in the female reproductive tract of the rat. Distribution of nerve fibres and motor effects. Neurosci. Lett. 39: 279284.

Straus, W. (1972) Phenylhydrazine as inhibitor of horseradish peroxidase for use in immunoperoxidase procedures. J. Histochem. Cytochem. 20:949951.

Tatemoto, K. (1982) Neuropeptide Y: Complete amino acid sequence of the brain peptide. Proc. Natl. Acad. Sci. U. S. A. 79: 5485.5489

Tatemoto, K., N. Carlquist, and V. Mutt (1982) Neuropeptide Y-A novel brain peptide with structural similarities to peptide $Y Y$ and pancreatic polypeptide. Nature 296: 659-660.

Weber, E., C. J. Evans, S. J. Samuelsson, and J. D. Barchas (1981) Novel peptide neuronal system in rat brain and pituitary. Science (N. Y.) 214 : $1248-1250$

Williams, R. G., and G. J. Dockray (1983) Immunohistochemical studies of FMRF-amide-like immunoreactivity in rat brain. Brain Res. 276: 213-229.

Yaksh, T. L., and T. A. Rudy (1976) Chronic catheterization of the spinal subarachnoid space. Physiol. Behav. 17: 1031 